\title{
Republic of Uzbekistan: Interim Poverty Reduction Strategy Paper- Joint Staff Advisory Note
}

The attached Joint Staff Advisory Note (JSAN) on the Interim Poverty Reduction Strategy Paper for the Republic of Uzbekistan, prepared by the staffs of both the World Bank and IMF, was submitted with the member country's Interim Poverty Reduction Strategy Paper (IPRSP) to the Executive Boards of the two institutions. A JSAN evaluates the strengths and weaknesses of a country's poverty reduction objectives and strategies, and considers whether the PRSP or IPRSP provides a sound basis for concessional assistance from the Bank and Fund, as well as for debt relief under the Enhanced Heavily Indebted Poor Countries (HIPC) Debt Initiative. The Boards then decide whether the poverty reduction strategy merits such support.

To assist the IMF in evaluating the publication policy, reader comments are invited and may be sent by e-mail to publicationpolicy@imf.org.

Copies of this report are available to the public from

International Monetary Fund • Publication Services

$70019^{\text {th }}$ Street, N.W. • Washington, D.C. 20431

Telephone: (202) 623-7430 • Telefax: (202) 623-7201

E-mail: publications@imf.org • Internet: http://www.imf.org

Price: $\$ 15.00$ a copy

\section{International Monetary Fund Washington, D.C.}





\title{
INTERNATIONAL DEVELOPMENT ASSOCIATION
}

\author{
AND \\ INTERNATIONAL MONETARY FUND \\ REPUBLIC OF UZBEKISTAN \\ Interim Poverty Reduction Strategy Paper \\ Joint Staff Advisory Note \\ Prepared by the Staffs of the International Development Association (IDA) \\ and the International Monetary Fund (IMF) \\ Approved by Shigeo Katsu (IDA) \\ and Julian Berengaut and Donal Donovan (IMF)
}

April 28, 2005

Contents

Page

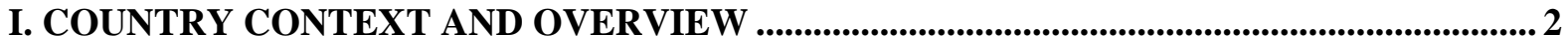

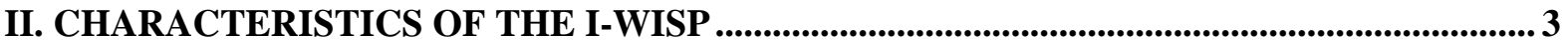

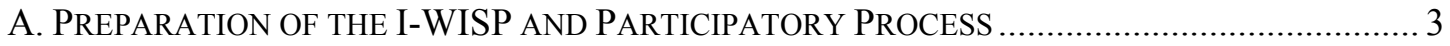

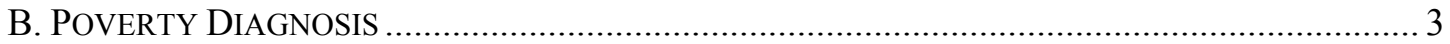

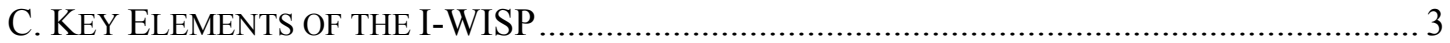

III. TOWARD A FULL WISP: PRIORITY AREAS FOR IMPROVEMENT ............................. 4

A. AFFIRMING COMMITMENT TO MARKET ECONOMY AND

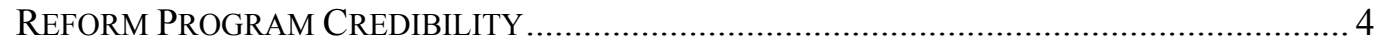

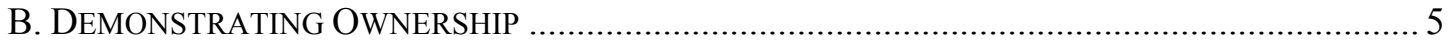

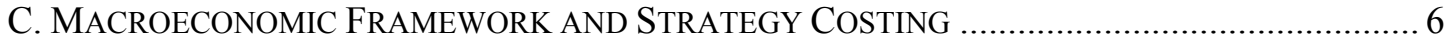

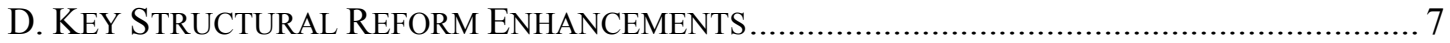

E. STRENGTHENING HUMAN DEVELOPMENT AND SOCIAL PROTECTION................................... 8

F. MONITORING AND EVALUATION OF THE I-WISP AND PREPARATION OF THE

FULL WISP

IV. CONCLUSION 


\section{COUNTRY CONTEXT AND OVERVIEW}

1. The Interim Welfare Improvement Strategy Paper for 2005-10 (I-WISP), ${ }^{1}$ officially transmitted to the International Development Association (IDA) and International Monetary Fund (IMF) on April 1, 2005, is the first comprehensive economic and social strategy document presented by the Uzbek authorities. It builds on several medium-term sectoral strategies, including the Production Localization, National Personnel Training, School Education Development, and Health Care Reform Programs. The staffs commend the authorities for the preparation of the I-WISP. The present Joint Staff Advisory Note (JSAN) is intended to provide guidance to the authorities on priority strategic issues to be addressed as they move forward with the preparation of a full Welfare Improvement Strategy Paper (WISP).

2. Uzbekistan's current macroeconomic situation is favorable. During 2000-03, the authorities addressed domestic and external imbalances, including large public sector deficits, a parallel foreign exchange market premium of over 400 percent, and declining trade volumes. Measures undertaken included allowing major devaluations (by some 600 percent between 2000 and 2003), limiting external borrowing, eliminating Central Bank financing of the budget, and adopting currency convertibility. Convertibility, coupled with favorable world market prices for gold and cotton-Uzbekistan's main exportsand increasing exports of natural gas and aircraft, contributed to large current account surpluses and substantial foreign exchange reserve growth. While real GDP growth averaged 2.9 percent between 1998 and 2003, it accelerated to around 7 percent in 2004, underpinned by rebounds in cotton production and trade. ${ }^{2}$

3. The pace of reforms, however, has been uneven, and living standards did not improve markedly in recent years. While some structural reforms, including in energy, agriculture, and public administration, have been implemented, the business environment still requires substantial improvement, as state control over the economy is pervasive. This is reflected in continued government ownership of major enterprises and banks, extensive administrative interventions in the economy such as restrictions on cash withdrawal and circulation and convertibility delays, and highly restrictive external and domestic trade regimes. The latest available data, based on the 2003 household budget survey and food poverty line $\mathrm{e}^{3}$ put poverty at 26 percent, close to its level in 2000-01, when the first internationally-comparable household survey was implemented in Uzbekistan. Uzbekistan, previously an IBRD-only borrower, became IDA-eligible in 2001 and, with per capita incomes (Atlas method) below $\$ 500$ in recent years, since 2004 it has had access to IDA credits only. Uzbekistan has not had an IMF financing program since the mid-1990s.

\footnotetext{
${ }^{1}$ The Interim Welfare Improvement Strategy Paper for 2005-10 (I-WISP) is the official name of an Interim Poverty Reduction Strategy (I-PRSP) in Uzbekistan.

${ }^{2}$ These numbers are based on alternative IMF staff estimates of real GDP growth, which have generally been lower than official estimates. Staff inflation estimates have been higher than official figures.

${ }^{3}$ See paragraph 5 below for a discussion of the poverty data limitations.
} 


\section{Characteristics OF THE I-WISP}

\section{A. Preparation of the I-WISP and Participatory Process}

4. The preparation of the I-WISP was led by the authorities, aided by consultants from a local consulting company, with donor support but limited civic participation. The staffs recommend that the participatory processes for the preparation of a full WISP be significantly enhanced. Work on the I-WISP began in early 2003. Following the presentation of a draft I-WISP to the donor community in May 2004, the I-WISP was finalized under the supervision of the Ministry of Economy, and presented to the donor community and select local civic organizations in February 2005. There has been no wide public discussion of I-WISP drafts or communications in the media about its preparation. The I-WISP, however, outlines in broad terms the consultation process for the full WISP that will involve stakeholders in discussions of the sectoral technical working groups and a series of workshops and consultations at the local government level. The authorities are encouraged to quickly develop details of the consultation process and involve a broad spectrum of non-governmental organizations in preparation of the full WISP. It is recommended that the full WISP provide a summary of public consultations held during its preparation and how they influenced its content.

\section{B. Poverty Diagnosis}

5. The staffs broadly agree with the poverty overview presented in the I-WISP and recommend a further strengthening of the quality of poverty monitoring and the capacity for poverty analysis. Since 2000, the Uzbek statistical agency has been carrying out, on a regular basis, a nationally representative Household Budget Survey (HBS), which provides information on socio-demographic characteristics of poverty. The I-WISP also appropriately draws on the work done by donors. The staffs broadly agree with the poverty analysis in the I-WISP that identifies the rural population as the greatest concentration of the poor, and indicates other population groups vulnerable to falling into poverty: large families with children, small town and rural populations with no access to land or with only household plots, seniors, and the disabled. The staffs encourage the authorities to improve the HBS, especially in measuring non-food consumption, as it does not allow the construction of a robust total consumption aggregate, which prevents reliable estimates of standard inequality measures and poverty rates relative to international (PPP) poverty lines. The authorities are also advised to strengthen monitoring of non-income dimensions of poverty and access to services, as well as build an in-house capacity for poverty analysis, including benefit incidence analysis.

\section{Key Elements of the I-WISP}

6. In the I-WISP, the authorities set the goal of reducing poverty by a quarter by 2010, through accelerating economic growth, strengthening human development, increasing equity and improving the environment, and aim to meet the Millennium Development Goal (MDG) by 2015. To achieve this, the WISP aims at the following: 
- Attaining high rates of economic growth through strengthening macroeconomic stability and accelerating structural reforms. The I-WISP highlights the need to increase the efficiency in the use of public and natural resources. It also recognizes the need to improve the business climate, including through a revision of the tax code, and the abolition of the "kartoteka" system that allows tax authorities to freeze taxpayers' bank accounts.

- Strengthening human development and social protection, focusing on access to public services, including in education, health and child welfare, and public utilities, and improving the labor market and social protection systems (including the introduction of pension reform), and ensuring gender equality.

- Reducing inter-regional inequalities in socio-economic development through targeted investment in less advantaged regions and equality of access to services regardless of place of residence. The objective is to be furthered by a decentralization of administrative responsibilities and the use of regional statistics for monitoring and feedback. The authorities have embarked on the preparation of regional poverty reduction strategies, a process that will continue in parallel with the preparation of the WISP.

- Improvement of the environment, through the development of comprehensive policies for environmental protection, including the promotion of clean technologies, improvements in ecological education, and the management of the country's natural reserves.

\section{TOWARD A FULL WISP: PRIORITY AREAS FOR IMPROVEMENT}

7. The staffs have identified several areas where the authorities' reform program could be strengthened in moving to a full WISP. These include clearly enhancing the commitment to market principles by breaking with the past strategy of import substitution and reliance on state intervention; demonstrating enhanced candor in assessing the economic and social issues facing the country; costing the proposed programs and putting them in a Medium-Term Budget Framework and a realistic macroeconomic framework; and specifying and prioritizing reform actions and development programs.

\section{A. Affirming Commitment to Market Economy and Reform Program Credibility}

8. The staffs strongly recommend that the authorities take advantage of the opportunity presented by the preparation of the full WISP to formulate an ambitious reform program and send a clear signal about their commitment to market reforms. In a wide range of sectors, the I-WISP outlines policies that the staffs consider positive initiatives. It also recognizes the importance of the private sector and foreign capital in economic development. However, in the staffs' opinion, the I-WISP does not represent a fundamental shift away from the development strategy pursued by Uzbekistan since independence, which has relied on achieving self-sufficiency through import substitution and industrialization through state intervention. The I-WISP gives no indication that 
some of the policies that have formed part of this strategy - agricultural state orders, the "localization" program, the highly restrictive foreign trade regime, state dirigisme through parastatals, planning, and administrative interventions - will be addressed soon. The staffs believe these policies are inefficient, detrimental to development, and unlikely to make Uzbek producers competitive on the world market, and encourage the authorities to use the opportunity presented by the preparation of the WISP to demonstrate their commitment to a liberal market economy.

\section{B. Demonstrating Ownership}

9. Demonstrated ownership and candor in the analysis of the economic and social situation will be important in establishing the credibility of the WISP. Commitment to poverty reduction at the highest level is critical for the success of a full WISP. The staffs encourage the approval of the full WISP at the Cabinet level or by the Parliament, which would clearly convey state ownership of the policies.

10. The I-WISP presents assessments of historical developments and the current situation in a wide range of sectors. The authorities are commended for grounding policy recommendations on empirical data and being frank in some of the assessments. However, in other cases the assessments appear to depict a more optimistic picture than could be supported by the diagnostic work done by international financial organizations. This applies, inter alia, to the analysis of poverty dynamics, past growth and inflation, the degree of success of industrialization policies, discussion of the employment generation record, progress in reforming state orders in the cotton sector, degree of state intervention in commercial bank and enterprise operations, and the privatization track record. In preparing a full WISP, the authorities are encouraged to consider more in-depth assessments of some of the indicated sectors. This would be critically important regardless of the pace of reform the authorities chose to adopt in the WISP. A sequenced reform strategy would need to be built around a list of priorities clearly grounded in a sound empirical analysis of the effectiveness of current policies.

\section{To be workable and credible, the reform program in the full WISP needs to be} specific and prioritized, and its impact adequately evaluated. The I-WISP covers the period to 2015 and lists a number of proposals, many of which are very general. As a result, a sense of priority and sequencing is missing, adversely affecting the credibility of the strategy. The staffs encourage the authorities, in preparing a full WISP, to focus on reforms to be undertaken in the next 3-5 years, work out the proposed policy actions and their linkages in detail and develop a realistic timetable for their implementation, paying attention to appropriate sequencing. The authorities would also benefit from a more explicit analysis of the intended impact of different reform measures, by conducting Poverty and Social Impact Assessments (PSIAs) of key planned reforms. Such assessments could be helpful in identifying measures to mitigate the impact of reforms on vulnerable groups. 


\section{Macroeconomic Framework and Strategy Costing}

\section{The staffs urge the authorities to strengthen the macroeconomic foundation of} the strategy and develop a comprehensive and realistic medium-term macroeconomic framework when preparing a full WISP. The I-WISP demonstrates the authorities' understanding of the importance of macroeconomic stability and reiterates their commitment to pursue monetary and fiscal policies aimed at maintaining favorable macroeconomic environment for structural reforms. However, the background macroeconomic overview should be substantially strengthened, and provide analysis of dynamics and interrelationships between the key domestic and external balances, the authorities' policy responses and existing macroeconomic vulnerabilities. The full WISP would also need to contain a complete macroeconomic framework, showing the planned sources of economic growth, savings and investment balances, foreign trade and external debt dynamics, and the expected impact of the economic growth on poverty and income distribution. In addition, the full WISP should be based on accurate assessments of past macroeconomic performance. The partial macroeconomic projections presented in the I-WISP envision annual real GDP growth of 7.5-8 percent over the period 2005-10. This is to be led by accelerated growth of value added in industry, averaging over 10 percent per annum. While economic growth in 2004 was around 7 percent, this was largely the result of the relaxation of convertibility restrictions, and favorable weather and world commodities market prices. Maintaining growth at such a level would require substantial economic liberalization and front-loading of reform, which the I-WISP does not envision. A credible WISP should have a macroeconomic scenario that is both realistic and consistent with the envisaged pace of economic reform.

\section{The full WISP should include a comprehensive Medium-Term Budget} Framework (MTBF) which integrates estimated costs of proposed policies and programs and provides a financing plan. The I-WISP presents the outlines of the first MTBF prepared by the authorities. The MTBF envisions an increase in current social spending of around 1 percentage point of GDP between 2003 and 2007, despite the overall decline of state budget expenditures by some 2 percentage points of GDP. However, domestically-financed centralized investment in social sectors is not included in this social spending and the coverage of the MTBF is limited, as most externallyfinanced investment projects are off-budget. Since no costing of policy measures in the I-WISP was undertaken and the participation of line ministries in its preparation was limited, the MTBF is not aligned with the I-WISP and is indicative only of the direction of aggregate fiscal policy. As the preparation of the full WISP proceeds, the integration of the WISP with the MTBF will be critical: it will impose a hard budget constraint on the planners and provide a way to prioritize policy measures and investments. In the process, close collaboration between the WISP working groups and the Ministry of Finance will be required. In this context, the planned creation of a dedicated working group on costing the full WISP is welcome. However, to increase its effectiveness, its composition, currently envisioning only the Ministry of Finance and Ministry of Economy, should include the line ministries. Provided a credible full WISP, integrated with a sustainable MTBF, is adopted, incremental financing may be supplied by donors and international financial organizations. 


\section{Key Structural Reform Enhancements}

14. In the staffs' opinion, the binding constraint on economic growth and poverty reduction in Uzbekistan is the extensive state intervention and the relatively closed nature of the economy, which holds back private sector development and employment generation. The staffs, therefore, encourage the authorities to be ambitious in designing the structural reform agenda for the full WISP in the following areas:

- Liberalizing the agricultural sector: With the rural population accounting for the majority of the poor, the elimination of constraints on income growth in rural areas would be a particularly pro-poor policy. The authorities' recent recognition of the growth potential of the agricultural sector is encouraging. Since 2003, an accelerated restructuring of agricultural cooperatives into leasehold farms has been undertaken, and state order prices of wheat and cotton were raised. The authorities are urged to move forward with the liberalization agenda, including the elimination of state orders (mandatory cropping patterns, state purchases, etc.) for wheat and cotton, and liberalization of input supply, marketing, and exports.

- Liberalizing the business environment: The I-WISP recognizes the importance of the private sector, especially small-scale enterprises. Yet, the enterprise sector has to contend with state control and interventions from industry-wide parastatals and local authorities, and operate under the guidance of a variety of state plans. In the full WISP, the authorities are encouraged to advance the private sector development agenda - reduce state planning, input and output distribution, and interventions in enterprise and bank operations; dissolve parastatal industrial associations; and substantially accelerate privatization and foreign and domestic trade liberalization. The full WISP would also benefit from a comprehensive review of all regulations, restrictions and barriers to entry for private businesses. It should also reaffirm the inviolability of property rights by discussing issues of legal recourse, including against the state, and independence of the judiciary.

- Developing the financial sector: The WISP should offer a comprehensive discussion of financial market reforms. In addition to ending cash shortages, the strategy should be enhanced by the removal of (i) the role for banks in tax administration and financial control, (ii) the requirement for retail establishments to deposit cash proceeds daily, (iii) the distinction between cash and non-cash payments, and (iv) surrender requirements.

- Strengthening governance: The I-WISP contains measures on decentralization, administrative reform, and publication of data, but several of these measures are quite general. The authorities are urged to specify measures in the full WISP to substantially increase transparency, including improved data quality and wider data dissemination; eliminate legal restrictions on the publication of macroeconomic data; limit secret clauses and resolutions in legally binding 
documents; undertake civil service reform; and strengthen the fight against corruption.

\section{E. Strengthening Human Development and Social Protection}

15. The staffs welcome the authorities' attention to education and encourage them to further address efficiency, financing, and equity issues in the sector. The I-WISP outlines education development policies for the pre-school through vocational levels, aiming at improving the quality of school facilities, textbooks, teaching personnel, and professional relevance of vocational training, as well as transferring to capitation financing. In developing the full WISP, the staffs recommend that the authorities also pay attention to improving the efficiency of education spending, including through financing arrangements to stimulate performance and reduce disparities in quality of education, reviewing the appropriateness of the vocational training approach to upper secondary education, and improving the access of low-income groups to education, including by addressing informal payments.

16. Health care reforms should focus on improving access to services, and increasing efficiency in the sector. The I-WISP envisions improvements in primary, emergency and specialized health care, preventive health measures, and a gradual transition to output-based financing. The authorities are encouraged to improve financing arrangements to address the existing regional and rural-urban inequities in health expenditures, provide regional health managers with flexibility and incentives to manage resources more efficiently, and ensure access of the vulnerable to health care and protect them against heavy medical costs and informal payments. Issues related to the management of the pharmaceutical supply and access of the poor to drugs should also be reflected in the WISP.

17. Social protection in Uzbekistan needs to be strengthened and better targeted. In the I-WISP, the authorities recognize the need to improve the social protection system and address the sustainability of the pension system. Measures envisioned for this include cuts in non-means-tested privileges, replacement of in-kind benefits with monetary compensation, the gradual introduction of targeted utility subsidies, greater decentralization in managing allowances, and introduction of a cumulative pension system. The staffs support these policies and recommend creation of mechanisms to protect the vulnerable against energy and utility price increases, and a reorientation of the Employment Promotion Fund from job creation or lending schemes to funding adequate unemployment benefits and job counseling. The staffs urge the authorities to ensure a careful analysis of the transition costs of the cumulative pension system and recommend consideration of changes to the system to reduce social security taxes.

\section{F. Monitoring and Evaluation of the I-WISP and Preparation of the Full WISP}

18. The I-WISP recognizes the need to improve monitoring and evaluation systems, including reconciling inconsistent data sources. For instance, data from the Demographic and Health Survey conducted in 1996 and 2000 reveal higher rates of 
infant and maternal mortality than official statistics. Estimates of real GDP growth and inflation by the staffs diverge from official figures. Improving the quality and consistency of national statistics is a long term process, but the full WISP should be upfront about alternative information and make use of independent survey instruments to complement official statistics in setting performance benchmarks and monitoring implementation.

19. The staffs welcome the intention to set up an institutional structure to support the development of the WISP, including the creation of a Coordination Council headed by the First Deputy Prime Minister. The authorities are encouraged to ensure adequate representation in the working groups of non-governmental organizations, local authorities, and parliamentary committees, as well as consider assigning full time staff to act as a dedicated secretariat for the WISP. The formalization of the institutional structure will need to proceed quickly given the ambitious timetable for the preparation of the full WISP, which envisions its completion by February 2006.

20. In developing the full WISP, the authorities are advised to pay greater attention to the economic and implementation risks. The I-WISP identifies some risks, such as the possibility of a weak linkage between economic growth and poverty reduction, and inadequacy of monitoring and evaluation of performance under the I-WISP. However, more analysis is needed on macroeconomic risks, particularly external and domestic shocks.

\section{CONCLUSION}

21. The preparation of the I-WISP is an important step toward creating a sustainable development strategy and initiating a national dialogue on economic policies and living standards. The I-WISP provides outlines of economic and social policies in most key sectors, and contains many actions essential for accelerated growth and poverty reduction. The staffs welcome the informative poverty diagnostics in the strategy, the four broad pillars of the I-WISP and the authorities' intention to institutionalize and promptly move ahead with the process of preparing the full WISP.

22. At the same time, the staffs have identified a number of priority areas where action is needed to make the full WISP an effective and credible program of economic growth and poverty reduction. These actions include the following:

- Establish the credibility of the strategy by (i) providing a candid assessment of economic and social situation and trends; (ii) improving the quality and consistency of data and strengthening poverty monitoring mechanism; (iii) specifying and prioritizing policy actions within a clear timetable; and (iv) demonstrating ownership of the strategy by publicly endorsing it at the highest levels of the government;

- Formulate an ambitious strategy that would decisively break with the importsubstitution policies and state interventionism of the past and convey 
Uzbekistan's commitment to market reforms;

- Strongly advance the structural reform agenda, particularly in the areas of agricultural reform, financial sector reform, private sector development, property rights protection, the domestic and external trade regimes, tax administration, governance, and transparency;

- Strengthen human development and social protection policies, particularly as regards the efficiency, equity and financing of education, health care, and social benefits spending, as well as the fiscal sustainability of the pension system;

- Underpin the strategy with a comprehensive and realistic macroeconomic framework and ensure fiscal sustainability of the strategy by formulating it within the hard budget constraint of an MTBF;

- Significantly enhance the consultative processes to seek and incorporate views of all stakeholders and generate a sense of participation in policy making among the general public.

23. Executive Directors' views are sought on whether they agree with (i) the need for the authorities to formulate an ambitious WISP that would credibly demonstrate their commitment to market reforms; (ii) the assessment of the medium-term macroeconomic prospects; (iii) the proposed areas of special focus in structural and social sector reforms; and (iv) the need for a significantly enhanced participatory process and transparency in preparing the full WISP. 